\title{
Scaling Community Pharmacy Transformation with the 'Flip the Pharmacy' Implementation Model: Program Origins
}

\author{
Anne Marie Sesti Kondic, PharmD ${ }^{1}$; Troy Trygstad, PharmD, MBA, PhD²; Randy McDonough, PharmD, MS, BCPS, BCGP3; \\ Matt Osterhaus, BSPharm, FAPhA, FASCP4 \\ ${ }^{1}$ Community Pharmacy Foundation, Chicago, Illinois; ${ }^{2}$ Pharmacy and Provider Partnerships, Community Care of North Carolina; \\ ${ }^{3}$ Towncrest Pharmacy, lowa City, IA; ${ }^{4}$ Osterhaus Pharmacy Maquoketa, IA
}

\begin{abstract}
The rising costs of healthcare, increased chronic illnesses, and healthcare provider burnout has led to an environment desperate for scalable solutions to ease practice burdens. With a projected shortage in the number of primary healthcare providers available to provide team-based care, community-based pharmacy practitioners are accessible and eager to assist. In order to provide enhanced patient care services to aid their clinician colleagues, community-based pharmacists will have to transform their practices to support the provision of enhanced services and medication optimization in value-based payment models. The purpose of this article is to define how multiple factors in pharmacy, healthcare, technology and payment models aligned to create an opportunity for the Community Pharmacy Foundation and CPESN ${ }^{\circledR}$ USA to implement a nationwide community pharmacy practice model called 'Flip the Pharmacy'. This new model aims to scale community pharmacy practice transformation and move beyond filling prescriptions at a moment-intime to caring for patients over time through a 24-month step-wise program paired with in-person pharmacist coaching. Preliminary observations from the first six months of the program highlight community pharmacy as a site of care with community-based pharmacist practitioners providing and documenting targeted patient care interventions.
\end{abstract}

Keywords: Community Pharmacy, Practice Transformation, Innovation, Grants

\section{Introduction}

The escalating costs of healthcare coupled with chronic illness in an aging population along with healthcare provider burnout have created an environment gasping for scalable solutions to ease practice burdens. ${ }^{1-3}$ Also, the projected shortage $(21,400-$ $55,200)$ of primary care physicians by 2033 increases the difficulty of providing team-based care, making communitybased pharmacy as a site of care increasingly appealing. ${ }^{4}$ With over 62,000 community pharmacies nationwide and $89 \%$ of Americans living within five miles of a community pharmacy, community-based pharmacist practitioner (CPP) are accessible and eager to assist. ${ }^{5-8}$

To assist their clinician colleagues, CPP must transform their practices to support the provision of enhanced services and medication optimization. ${ }^{9}$ This transformation can be accomplished by moving from a dispensing-focused practice to one in which enhanced patient care services are integrated and performed during the normal workflow. Therefore, changes in staffing, use of technology, and implementation of patient management strategies that promote efficient patient care processes (e.g., medication synchronization integrated with the appointment-based model) will be required. On this premise, we introduce 'Flip the Pharmacy' launched by the Community Pharmacy Foundation (CPF) and CPESN ${ }^{\circledR}$ USA that aims to move beyond filling prescriptions at a moment-in-time time to caring for patients over time (Figure 1). ${ }^{10}$

Corresponding author: Anne Marie Sesti Kondic, PharmD

Executive Director, Community Pharmacy Foundation

980 N Michigan Avenue, Suite 1400, Chicago, IL 60611

www.CommunityPharmacyFoundation.org

Email: amkondic@CommunityPharmacyFoundation.org
Flip the Pharmacy (FtP) is a 24-month program consisting of six practice transformation domains (Figure 2) repeated through four progression cycles, each with a different medication optimization focus. The four progressions include hypertension, opioid stewardship and pain management, diabetes/immunizations and behavioral health/social determinants of health (SDoH). Unique and succinct FtP Change Packages are created for each domain within each of the progressions. A Change Package is defined as an evidencebased set of changes that are critical to the improvement of an identified care process. ${ }^{11}$ Each FtP pharmacy will focus on a monthly Change Package innovation while continuing to build longitudinal patient care services and documentation over time. Implementation of the Change Package is a coordinated process whereby the FtP coordinating center (CPESN ${ }^{\circledR}$ USA) creates the change package utilizing subject matter experts (SMEs), current guidelines, and evidence-based literature. Supplemental educational materials are developed to enhance the pharmacy staff's learnings on the topic. Once the Change Package is created, it is reviewed with the Practice Transformation Team (PTT) Leads and Coaches before release to the cohort pharmacies. The Change Package is released at the beginning of the month, PTT Coaches will provide training/coaching for each site, monitor their progress, and provide remediation as needed. At the end of two years, each FtP pharmacy will have implemented six separate domains in each of the four progressions for a total of 24 Change Packages. The metrics that are being measured to determine practice transformation implementation are the number of e-Care Plans submitted, medication-related problems identified, clinical interventions made, care coordination documented, and patient level clinical monitoring parameters collected (e.g., blood pressures, blood sugars, hemoglobin A1c). 
Looking at the FtP program through the lens of a management book titled, Awaken, Align, Accelerate: A Guide to Great Leadership $^{12}$, we describe the origins of the program using examples of how community pharmacy practice was 'Awakened' with early innovations such as the Ashville Project. ${ }^{13}$ Healthcare systems and providers, technology advancements and changes to payment models became more 'Aligned' and created a willingness to explore alternate patient care models. Finally, a clinically integrated network of community pharmacies, $\mathrm{CPESN}^{\circledR}$ USA, was established and could 'Accelerate' an idea to scale a community pharmacy transformation program. Rather than the perspective of an individual advancing oneself through the principles of a selfhelp book, think of a model where community pharmacy teams develop themselves with structured in-person coaching to connect the moving pieces of pharmacy practice transformation through an engaging and inspiring process.

\section{Awaken Potential}

The first phase, Awakening, advises leaders to assess their existing strengths and identify development opportunities while incorporating external feedback to provide clarity and motivation for future development. Examples of healthcare systems 'awakening' and partnering with community pharmacists to transform patient care delivery include the Ashville Project and Community Care of North Carolina (CCNC). 13-14

The aspirational foundation for community pharmacy transformation is having the capability for enhanced patient care services but lacking the workflow optimization to scale innovations.

The positive results of the 1997 Asheville Project, ${ }^{13}$ including improved adherence and clinical measures, the lower overall cost of care, and increased worker productivity are even more relevant in today's health and payment reform environment. The Ashville Project is just one of the hundreds of innovations in practice that ended up being limited singular projects without a mechanism for scaled implementation. ${ }^{15,16}$

A prime example of awakening to an opportunity for improved patient care occurred in 2013 when the physician leadership of CCNC, a state-wide patient-centered medical home, commissioned an analysis of Medicaid claims data. CCNC found that complex patients who were identified as needing complex care management visited the community pharmacy 35 times per year compared to 3.5 visits to their primary care provider. The CCNC pharmacy team's call to action was to develop a pharmacist coordination of care service model to capitalize on greater patient access within the pharmacy. CCNC engaged with Moose Pharmacy, a progressive advanced services pharmacy, and CCNC clinical leaders to connect with similar pharmacies across the state, creating a pharmacy network guaranteed to deliver similar quality services. ${ }^{14}$ This partnership led to the creation of CPESN $^{\circledR}$ and subsequent award of a three-year $\$ 15$ million grant from the Center for Medicare \& Medicaid Innovation (CMMI) to evaluate a model using community pharmacists to help lower costs and improve care for the state's 1.7 million Medicaid patients. ${ }^{17}$

Another awakening development was the emergence of the CPF that was founded in 2000 with a corpus of over $\$ 18$ million for the sole purpose of grant-making and resource sharing to advance the practice of community pharmacy. ${ }^{18}$ The uniqueness of these unrestricted funds to cultivate innovative ideas has greatly impacted community pharmacy practitioners, researchers, and the profession. ${ }^{19}$ Recent publications have summarized the distribution, scope, and impact of CPF grant funding, including how grant topics have evolved with the pharmacy practice eras of disease state management, pharmaceutical care, medication therapy management, and recently value-based care. ${ }^{20,21}$ Prior to FtP funding, CPF had awarded 192 grants over 18 years, with $\$ 9,591,179$ million to support grants and projects. ${ }^{22}$

The organizational natures of $\mathrm{CPESN}^{\circledR}$ USA and CPF were independently progressing on the 'awakening' ideas of community pharmacy transformation that would eventually lead to the alignment and acceleration to create the FtP program.

\section{Alignment}

Phase 2, Alignment, is the intersection of personal development goals and organizational needs to deliver strong results for today and into the future. Desired outcomes are explicitly defined to provide the business case and context for a leader's development goals. ${ }^{12}$

The 'organizational need' from a United States healthcare perspective is the consistently higher per capita health care spend and resulting in suboptimal patient outcomes. ${ }^{23}$ In turn, healthcare environments and technology advances have evolved and aligned to try and improve quality care. For example, federal legislation incentivized healthcare systems and providers to adopt meaningful use of interoperable electronic health records. ${ }^{24}$ For pharmacy, recent developments with standardized clinical healthcare terminology (e.g., SNOMED codes) and electronic data transfer standards (HL7 for the pharmacist eCare plan) have provided a sought after home to capture pharmacist-patient interactions, care planning, and clinical documentation. ${ }^{25}$ Documentation facilitates pharmacists' ability to quantify interventions associated with improved patient outcomes and propose solutions to providers and payers with this critical evidence to support collaborative team-based care. ${ }^{26}$ This interconnectivity, in turn, aligns with the emerging value-based payment models appearing in government and commercial plans. ${ }^{27,28}$ Value over volume incentivized payments are breaking down traditional siloed care models, and accountable care organizations (ACOs) are on the rise and demonstrating trends in Medicare ACO savings. ${ }^{29,30}$ 
Community pharmacy product-based reimbursement models are not sustainable nor reflective of current pharmacy practice that is high-touch patient care focused. ${ }^{26}$ Unpredictable direct and indirect remuneration ${ }^{31}$ fees threaten the financial viability of all pharmacies, but particularly those serving as critical access pharmacies in rural and medically underserved areas. ${ }^{32}$ Therefore, the pharmacy environment is aligning and ripe for a practice transformation effort to sustain community-based pharmacy. CPF and CPESN ${ }^{\circledR}$ USA recognized the opportune timing and developed the FtP program to guide pharmacies away from prescription dispensation at a moment-in-time and towards delivering patient-level care planning over time. This essentially creates the opportunity for 'accountable pharmacy organizations' where participating pharmacy teams provide high-quality, coordinated patient care and document interventions and outcomes. Over time, these intervention measures will support the transformed pharmacy business model leading to expressed value and payment for services.

Flip the Pharmacy goals align with the Joint Commission of Pharmacy Practitioners' (JCPP) vision, which recognizes "Patients achieve optimal health and medication outcomes with pharmacists as essential and accountable providers within patient-centered, team-based healthcare." ${ }^{33}$-The FtP concept evolved from the educational model of 'Flip the Classroom' ${ }^{34}$ by the Khan Academy in the early to mid-2000s, to 'Flip the Clinic'35 for doctor's offices supported by the Robert Wood Johnson Foundation between 2013 - 2017 and now, 'Flip the Pharmacy' for large scale community pharmacy transformation. The conceptual FtP model relies on CPF grantees and other community practice innovators contributing to FtP Change Package curriculum development and scaled implementation, thereby yielding program graduates that become innovators who reinvest in the transformational process (Figure 1). ${ }^{10}$

Flip the Pharmacy was born from the idea that there was no shortage of innovations created or nurtured by CPF, but rather what was missing was a significant financial investment and community-based pharmacy data and provider-network infrastructure to support and scale those innovations. Additionally, CPPs yearn for pathways that reward collaborative practice towards or at the top of their pharmacy licenses. As it stands, CPPs are grossly underutilized.

\section{Accelerate Performance}

Phase three, Accelerate, entails designing and deploying intentional development strategies that help enhance leadership performance on the most vital priorities. Nelson and Ortmeier state that this phase is the 'how' and 'when' of development and emphasizes the right mixture of challenge and support to maximize learning by being challenged without being overwhelmed. ${ }^{12}$

Two notable and 'intentional' accelerating factors contributed to the 'how and when' for the expeditious FtP program development, launch, and implementation.
First, Randy McDonough from Towncrest Pharmacy in lowa applied their innovative continuous medication monitoring process, known to yield successful outcomes of lowering total costs of care and better medication adherence with a commercial insurer, to other pharmacies in lowa and then a pilot FtP program in eastern Tennessee during the summer of 2019. ${ }^{36-38}$ Second, synergistic collaborations exploded between CPESN $^{\circledast}$ USA, FtP applicants, and the Academia-CPESN ${ }^{\circledast}$ USA Transformation (ACT) Pharmacy Collaborative bringing together pharmacy systems, pharmacy practice, and pharmacy educators, respectively (Figure 3). ${ }^{10,39}$ Additionally, many of the FtP Transformation Teams actively engaged and partnered with their state pharmacy associations for in-kind educational, technical and operational support for pharmacies in their respective states.

The FtP program was announced on June 27, 2019. Practice Transformation Teams (PTTs) who coordinate and fund coaches for participating pharmacies were selected and announced on September 4, 2019, and the inaugural FtP cohort launched their implementation efforts on October 1, 2019, with twenty-eight PTTs enlisting over 150 coaches (funded through CPF grants and by in-kind or monetary partner support) across over 500 pharmacies. ${ }^{40}$ The first cohort is nationally distributed, varied across urban, suburban, and rural settings, and the applications revealed several established and developing partnerships with payers and state health departments.

Over the planned five-year partnership, the program aims to graduate more than 1,000 pharmacies from a two-year transformation process and influence over 5,000 pharmacy locations. The Change Package is the 'how and when' of the FtP implementation. Emanating from the CMS-CMMI primary care transformation program (TCPI-Practice Transformation Networks) ${ }^{41}$ that targeted primary care transformation in preparation for Medicare Access and CHIP Reauthorization Act of 2015 (MACRA) ${ }^{42}$ implementation, the FtP Change Package is an evolving curriculum focused across six domains grounded in the Patient Care Process and documented longitudinal patient care planning. ${ }^{33,43}$ Content for the Change Package is developed using implementation science principles including 'teaching the why,' gaining buy-in, releasing information in bite-size chunks, coaching the intervention, assessing implementation fidelity (degree to which an intervention or program is delivered as intended), and using data to make decisions. ${ }^{44-47}$ The Change Package is publicly available on the FtP website for anyone interested in using the content. ${ }^{48}$

Additional program goals include lofty targets for non-productbased reimbursement revenue, care plan submissions using HL7 standards, and screenings for behavioral health conditions and social determinants of health. Documented reductions in systolic blood pressure, $\mathrm{HbA1c}$ percentages, and cholesterol in patients with associated chronic conditions will provide a concrete measurement of the impact of the project. Ongoing data analysis and dashboarding will be provided monthly to the 
teams to monitor progress as well as provide incremental feedback to the FtP administrators.

The FtP program has preliminary results from the first 6-months of implementation that are inspiring. Participating pharmacists and staff implemented changes within their practices to support enhanced patient care services, which resulted in a total of 94,253 care plans being submitted within the first 6 months of the program (ending March 2020). ${ }^{49}$ The pharmacy teams embraced the guidance in Progression 1 Change Packages (hypertension focus) to document 17,546 patient systolic and diastolic blood pressure results obtained during patient encounters at the pharmacy, representing $18.6 \%$ of care plan submissions within the same six-month period (October to March 2020). ${ }^{49}$ Pharmacists documented medication related problems and provider communications in the eCare plan care coordination notes for ongoing patient care monitoring which can be used in future analyses to quantify the impact of the interventions on patient care outcomes longitudinally. There is continued excitement, energy, and a renewed sense of professional purpose within the FtP teams to deliver on the value-based healthcare challenge to provide quality patient care utilizing the primary asset of CPP, meeting the patient where they are, and to provide that care in partnership with the growing cadre of other health care facilitators and clinician providers.

\section{Conclusions}

The spark for the FtP program originated from two organizations; one financially capable and the other operationally committed to transforming community pharmacy practice. CPF and CPESN ${ }^{\oplus}$ USA believe that community pharmacies and pharmacists are awake and ready for change; healthcare delivery, technology, and payment reforms are aligning; and, CPPs are ready to accelerate from singular practice transformation evolutions to a nationwide scalable community pharmacy practice revolution. Preliminary FtP results highlight the benefit of community pharmacy as a site of care with CPPs offering a much-needed opportunity to decrease the burden placed on our clinician colleagues and contribute to improving patient care.

Funding: This research did not receive any specific grants from funding agencies in the public, commercial, or not-for-profit sectors

\section{Author contribution statement:}

Anne Marie (Sesti) Kondic: Conceptualization, Visualization, Project administration, Writing - original draft

Troy Trygstad: Conceptualization, Visualization, Writing review \& editing

Randy McDonough: Visualization, Writing - review \& editing Matt Osterhaus: Visualization, Writing - review \& editing

\section{Disclosure of conflicts of interest:}

Anne Marie Kondic is Executive Director and Grants Administrator for the Community Pharmacy Foundation (CPF), Troy Trygstad is employed by CCNC and Executive Director of CPESN, who is contracted as the FtP Coordination Center, Randy McDonough is a CPF grantee, FtP Director of Practice Transformation, and co-owns a FtP participating pharmacy, Matt Osterhaus owns Osterhaus Pharmacy, a FtP participating pharmacy, and is President CPESNIOWA, Treasurer CPESN-USA, and Treasurer of CPF

\section{Acknowledgments:}

CPF Board of Directors -

Phil Burgess, RPh, Chicago, Illinois (President)

Linda Garrelts MacLean, RPh, Spokane, Washington (Vice President)

Matthew Osterhaus, BSPh, Maquoketa, lowa

(Secretary/Treasurer)

Brian Jensen, RPh, Two Rivers, Wisconsin

Dorinda Martin, PharmD, Austin, Texas

Randy Myers, RPh, Carey, Ohio

Steve Simenson, BPharm, Anoka, Minnesota

\section{CPF Emeritus -}

Lonnie Hollingsworth, PD, Lubbock, Texas [Board of Directors] Frank J. McGarr, US District Court (retired), Downers Grove, Illinois [Board of Directors]

Robert J. Osterhaus, RPh, Maquoketa, lowa [Board of Directors] Carlos Ortiz, RPh, Amherst, Massachusetts [Board of Directors] Louis M Sesti, RPh, Williamston, Michigan [Executive Director]

Medical Writing Support -

Brittany Hoffmann-Eubanks, PharmD, MBA; Banner Medical LLC

\section{References}

1. Dyrbye LN ST, Sinsky CA, Cipriano PF, et al. Burnout among health care professionals a call to explore and address this underrecognized threat to safe, high-quality care. National Academy of Medicine. https://www.amaassn.org/sites/ama-assn.org/files/corp/mediabrowser/public/ipp/i17-ipps-lotte-dyrbye-burnoutamong-health-care-professionals.pdf. Published 2017. Accessed 20 June 2020.

2. Dall TM, Gallo PD, Chakrabarti R, et al. An aging population and growing disease burden will require a large and specialized health care workforce by 2025. Health Affairs.

https://www.healthaffairs.org/doi/full/10.1377/hlthaff. 2013.0714. Published 2013. Updated 2017-08-02.

Accessed 20 June 2020.

3. Pennic F. Why clinician burnout is a public health crisis demanding urgent action.

https://hitconsultant.net/2019/07/15/survey-clinicianburnout-is-a-public-health-crisis-demanding-urgentaction/. Published 2019. Updated 2019-07-15. Accessed 20 June 2020.

4. AAMC. The complexities of physician supply and demand: projections from 2018 to 2033. Published 2020. https://www.aamc.org/system/files/202006/stratcomm-aamc-physician-workforce-projectionsjune-2020.pdf. Accessed July 23 July 2020. 
5. National Association of Chain Drug Stores. NACDS chain member fact book 2017 - 2018. NACDS (Subscription Required).

https://www.nacds.org/membership/resources/. Published 2017. Updated 2016-02-05. Accessed 20 June 2020.

6. Somma-McGivney MA, Pope DD, Trygstad T. Unrealized potential and unrecognized value: community-based pharmacy practice is reinventing itself - join the movement. American College of Clinical Pharmacy. 2019;2:330-334.

7. Bennett M, Goode JV. Recognition of community-based pharmacist practitioners: Essential health care providers. J Am Pharm Assoc (2003). 2016;56(5):580583.

8. PCMA. Independent Pharmacies in the U.S. are More on the Rise than on the Decline. PCMA,. Published 2020. https://www.pcmanet.org/wpcontent/uploads/2020/03/FINAL_IndependentPharmacies-in-the-U.S.-are-More-on-the-Rise-than-onthe-Decline.pdf. Accessed 17 July 2020.

9. Fay AE, Ferreri SP, Shepherd G, Lundeen K, Tong GL, Pfeiffenberger T. Care team perspectives on community pharmacy enhanced services. J Am Pharm Assoc (2003). 2018;58(4s):S83-S88.e83.

10. Flip the Pharmacy. It's time to flip the pharmacy. FtP. https://www.flipthepharmacy.com. Published 2019. Accessed 20 June 2020.

11. Improving Chronic Illness Care. Resource Libray: CAACCC Change Package. Published 2020. Accessed 20 June 2020.

12. MDA Leadership Consulting. Awaken, align, accelerate: a guide to great leadership. Edina, MN: Beaver's Pond Press; 2011.

13. Cranor CW, Bunting BA, Christensen DB. The Asheville Project: long-term clinical and economic outcomes of a community pharmacy diabetes care program. J Am Pharm Assoc (Wash). 2003;43(2):173-184.

14. CPESN. A leader in the value-based pharmacy movement - part one I CPESN USA. https://www.cpesn.com/newsroom/new-news-item/. Published 2019. Accessed 20 June 2020.

15. Trygstad T. I am living proof that atul gawande's cheesecake factory missed the mark when it comes to patient-centered care. Pharmacy Times. https://www.pharmacytimes.com/publications/issue/20 18/july2018/i-am-living-proof-that-atul-gawandescheesecake-factory-missed-the-mark-when-it-comes-topatientcentered-care. Published 2018. Accessed 20 June 2020.

16. Bauer MS, Damschroder L, Hagedorn H, et al. An introduction to implementation science for the nonspecialist. BMC Psychol. 2015;3:32.

17. American Pharmacists Association. CMS-funded project to create community pharmacist network. APhA. https://www.pharmacist.com/article/cms-fundedproject-create-community-pharmacistnetwork?is_sso_called=1. Published 2020. Accessed 20 June 2020.
18. Community Pharmacy Foundation. History \& origin. The CPF. https://communitypharmacyfoundation.org/about/. Published 2019. Accessed 20 June 2020.

19. Hoffmann-Eubanks B, Kondic AM, Isetts BJ. Alignment of community pharmacy foundation grant funding and the evolution of pharmacy practice in the United States of America. Pharmacy. 2019;7(2):63.

20. Isetts $B$, Olson AW, Kondic AM, et al. An evaluation of the distribution, scope, and impact of community pharmacy foundation grants completed by academic principal investigators between 2002 and 2014. Innovations in Pharmacy. 2017;8:1-10.

21. Olson AW, Isetts $B$, Kondic $A M$, et al. Comparing the research contributions of community pharmacy foundation funding on practice innovation between nonacademics and academics. Innovations in Pharmacy. 2017;8(3):1-8.

22. Community Pharmacy Foundation. The community pharmacy foundation. The CPF. https://communitypharmacyfoundation.org/. Published 2019. Accessed 20 June 2020.

23. Tikkanen R AM. U.S. Health Care from a Global Perspective, 2019 | Commonwealth Fund. The Commonwealth Fund,. https://www.commonwealthfund.org/publications/issu e-briefs/2020/jan/us-health-care-global-perspective2019. Published 2020. Accessed 20 June 2020.

24. Centers for Disease Control and Prevention. Public health and promoting interoperability programs. CDC. https://www.cdc.gov/ehrmeaningfuluse/introduction.ht ml. Published 2019. Updated 2019-09-10T03:12:20Z/. Accessed 28 June 2020.

25. Community Pharmacy Foundation. Pharmacy eCare initiative. what is the pharmacist electronic care plan? The Community Pharmacy Foundation. https://www.ecareplaninitiative.com. Published 2019. Accessed 28 June 2020.

26. Kliethermes MA. Value-based payment: preparing for changes in payment for services. Pharmacy Today. 2019;25(9):44-53.

27. Tu T, Muhlestein D, Kocot SL, et al. Origins and future of accountable care organizations. Leavitt Partners/Brookings Instititution. https://leavittpartners.com/wpcontent/uploads/2018/05/2015_Origins-and-Future-ofAccountable-Care-Organizations.pdf. Published 2015. Accessed 28 June 2020.

28. CMS.gov. Innovation models center for medicare \& medicaid innovation. Centers for Medicare and Medicaid Services. https://innovation.cms.gov/initiatives/\#views=models. Published 2019. Accessed 28 June 2020.

29. Castellucci M. CMS saved $\$ 739$ million last year from medicare ACOs. Modern Healthcare. https://www.modernhealthcare.com/payment/cmssaved-739-million-last-year-medicare-acos. Published 2019. Accessed 8 July 2020. 
30. Muhlestein D, Saunders RS, Richards R, et al. Recent progress in the value journey: growth Of ACOs and value-based payment models in 2018. Health Affairs Blog.

https://www.healthaffairs.org/do/10.1377/hblog201808 10.481968/full/. Published 2018. Accessed 8 July 2020.

31. Balick R. Pharmacies and policy makers are clawing back at DIR fees. The American Pharmacists Association. https://www.pharmacist.com/article/pharmacies-andpolicy-makers-are-clawing-back-dirfees? is_sso_called=1. Published 2018. Accessed 8 July 2020.

32. Elwell D. Critical access pharmacies' self-attest criteria. Illinois Department of Healthcare and Family Services https://www.illinois.gov/hfs/MedicalProviders/notices/ Pages/prn190308a.aspx. Published 2019. Accessed 21 July 2020.

33. Burns A. What is the pharmacists' patient care process, and why is it important? Pharmacy Today. 2018;24(4):50-51.

34. AdvanceHE. Flipped learning. Advance HE. https://www.heacademy.ac.uk/knowledge-hub/flippedlearning-0. Published 2018. Accessed 23 July 2020.

35. Robert Wood Johnson Foundation. About flip the clinic. Flip the Clinic. https://fliptheclinic.org/about/. Published 2019. Accessed 8 July 2020.

36. Doucette WR, McDonough RP, Herald F, et al. Pharmacy performance while providing continuous medication monitoring. J Am Pharm Assoc. 2017;57(6):692-697.

37. McDonough R. Practice transformation training and deployment of a practice transformation coach to implement CoMM, care plans, and enhanced services in a cohort of community pharmacies partnering with an ACO. The Community Pharmacy Foundation. https://www.communitypharmacyfoundation.org/grant s/grants_list_details.asp?grants_id=71839. Published 2019. Accessed 23 July 2020.

38. McDonough R. Implementation of continuous medication monitoring in a cohort of community pharmacies.

https://www.communitypharmacyfoundation.org/grant s/grants_list_details.asp?grants_id=71677. Published 2019. Accessed 8 July 2020.

39. ACT Pharmacy Collaborative. Bringing vision: transforming community pharmacy practice together. ACT Pharmacy Collaborative. https://www.actforpharmacy.com. Published 2019. Accessed 8 July 2020/
40. CPESN, Community Pharmacy Foundation. Flip the pharmacy update. the CPF.

https://myemail.constantcontact.com/Flip-thePharmacy-

Update. html? soid=1127445762342\&aid=RdCkFaugg-g. Published 2019. Accessed 21 July 2020.

41. CMS.gov. Transforming clinical practice initiative. Centers for Medicare \& Medicaid Services. https://innovation.cms.gov/innovationmodels/transforming-clinical-practices. Accessed 23 July 2020.

42. CMS.gov. MACRA. Centers for Medicare and Medicaid Services. https://www.cms.gov/Medicare/QualityInitiatives-Patient-Assessment-Instruments/ValueBased-Programs/MACRA-MIPS-and-APMs/MACRAMIPS-and-APMs. Published 2019. Accessed 8 July 2020.

43. Practitioners JCoP. The pharmacists' patient care process. https://jcpp.net/patient-care-process/. Published 2014. Accessed 8 July 2020.

44. Carroll C, Patterson M, Wood S, et al. A conceptual framework for implementation fidelity. Implementation Science. 2007;2(1):1-9.

45. Livet $M$, Haines ST, Curran GM, et al. Implementation science to advance care delivery: a primer for pharmacists and other health professionals. Pharmacotherapy. 2018;38(5):490-502.

46. PBISApps. 7 keys to real world implementation. PBISApps.

https://www.pbisapps.org/community/Pages/7-Keys-toReal-World-Implementation.aspx. Published 2019. Accessed 20 July 2020.

47. Rapport F, Clay-Williams R, Braithwaite J, et al. The struggle of translating science into action: Foundational concepts of implementation science. J Eval Clin Pract. 2017;24(1).

48. Flip the Pharmacy. Pilot period materials and results. FtP. https://www.flipthepharmacy.com/changepackages. Published 2019. Accessed 21 July 2020

49. Flip the Pharmacy. Unprecedented times...unwavering commitment to our patients and our communities. Published April 2020. https://myemail.constantcontact.com/Flip-thePharmacyUpdate.html?soid=1127445762342\&aid=4shZO-Mc0pg. FtP. Accessed 26 July 2020. 


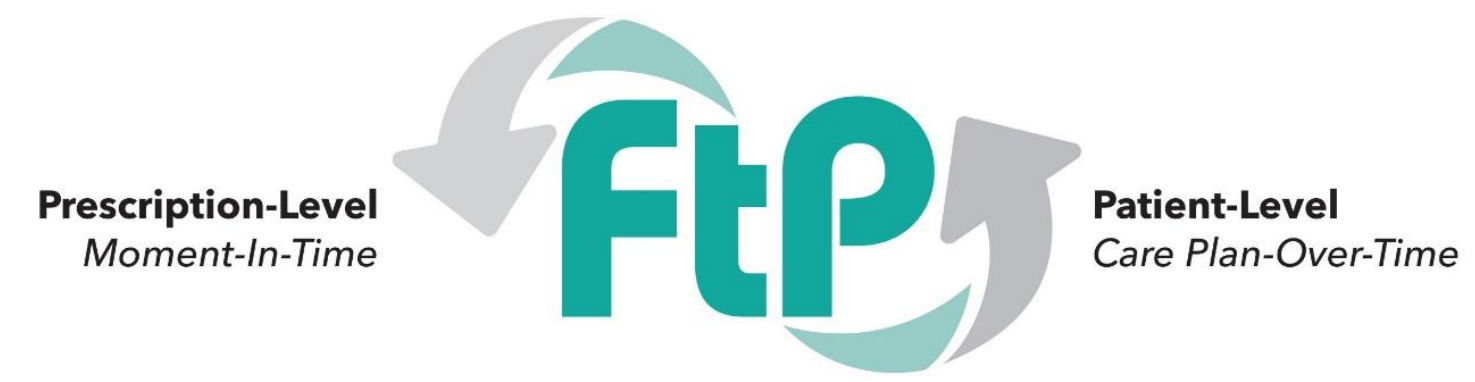

Moving beyond filling prescriptions at a moment in time, to caring for patients over time.

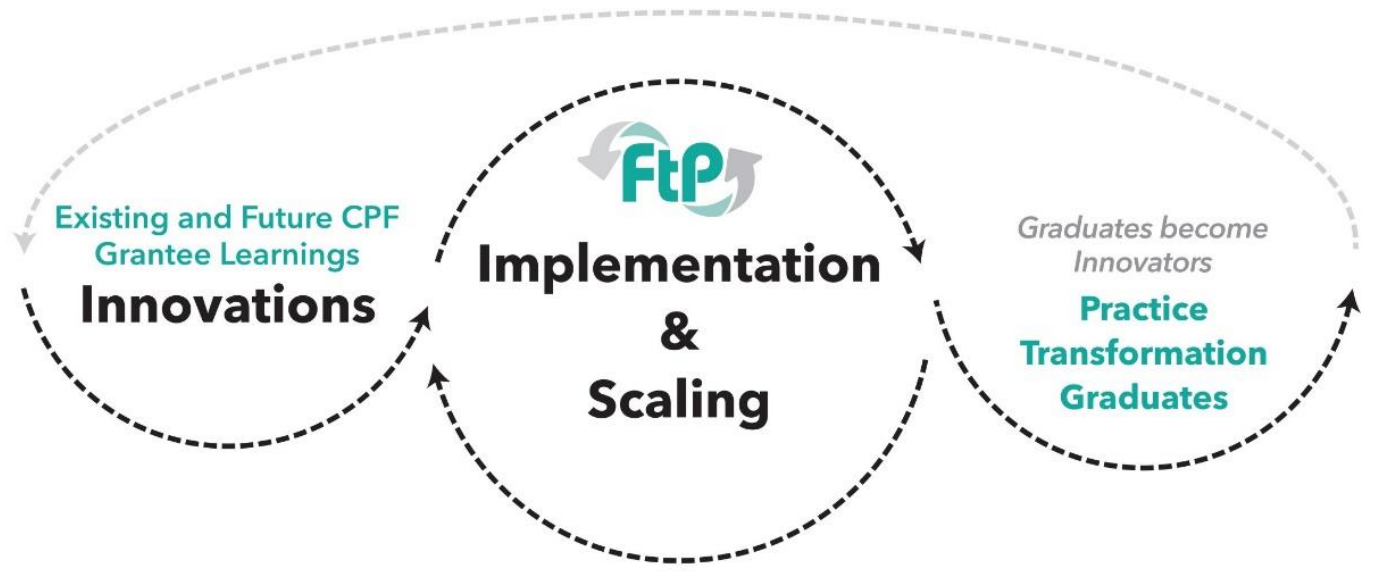

Figure 1. Flip the Pharmacy (FtP) Community Pharmacy Transformation Program 


\section{Domains}
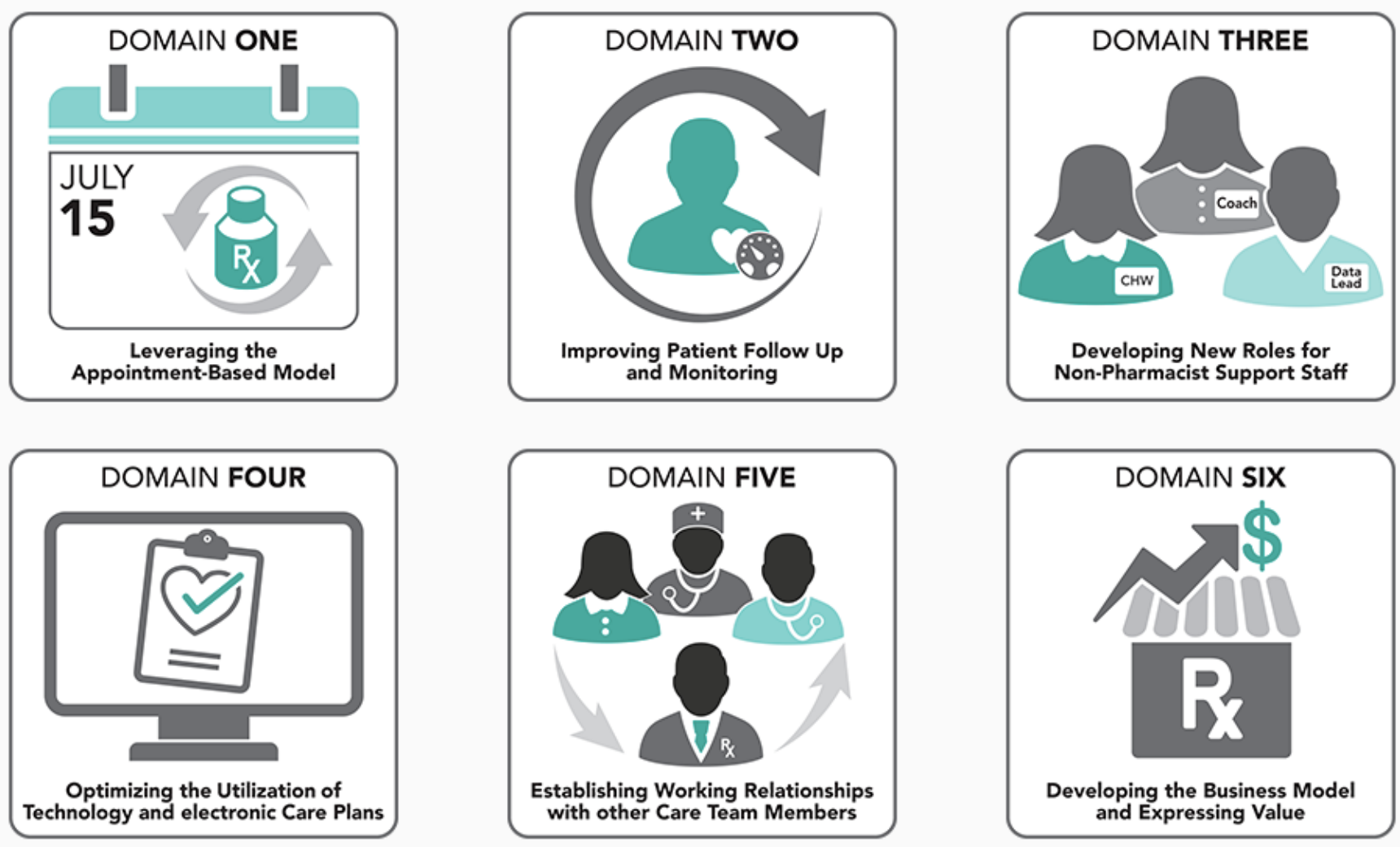

Figure 2. Flip the Pharmacy Practice Transformation Domains 


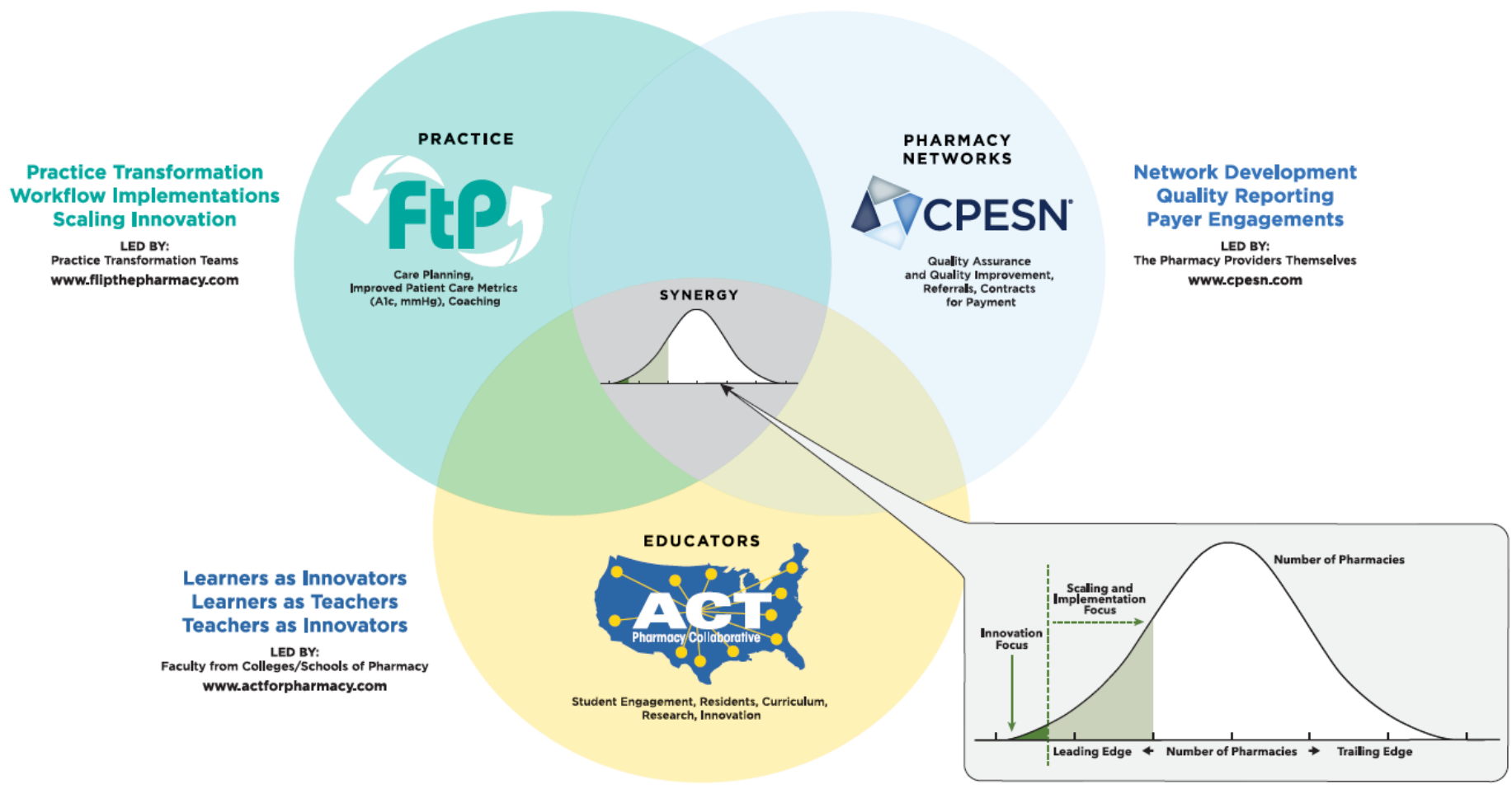

Figure 3. Programmatic Intersections of Pharmacy Networks, Practice and Educators Leading to Scaled Community-Based Pharmacy Innovation 